\title{
Overview of tuned liquid dampers and possible ways of oscillation damping properties improvement
}

\author{
Jans Velič̌ko, Līga Gaile \\ Riga Technical University, Department of Structural Mechanics
}

\begin{abstract}
Nowadays liquid tuned dampers are used in high-rise buildings and many others "dynamically sensitive" engineering structures. Liquid damper properties can be widely changed using different shapes of water containers, additional barriers inside, different types of liquid etc. Different types of liquid dampers exist or are proposed by researchers. Main types of liquid dampers are observed and compared in the paper.

One of the main disadvantages of the majority of liquid dampers is that only one main oscillation frequency is damped, that is not enough for the structures, where different vibrations modes are essential simultaneously. Existing solutions of this problem are examined in the paper.
\end{abstract}

Keywords: tuned mass dampers, tuned liquid dampers, damping, oscillation.

\section{INTRODUCTION}

Nowadays tuned dampers are the essential part of high-rise buildings and many others "dynamically sensitive" engineering structures. They are widely used in the world's highest buildings for the damping of wind and seismic induced mechanical vibrations and improvement of building dynamic behavior. As a result, higher and more flexible engineering structures can be built.

Main idea of vibration damper is that damper mass oscillates in counter phase to main structure. As a result amplitudes of main structure oscillations are reduced due to summation with damper oscillations.

So called tuned mass dampers - dampers where main mass is solid body elastically or viscoelastically connected with the main structure - are more widely distributed in engineering structures [31]. Connection stiffness is specially adjusted (tuned) to the particular structure vibration frequency to obtain the damping effect. The most straightforward type of tuned mass damper - a heavy sphere suspended on a cable at the top of the tower. This type of damper is widely used in high-rise building.

In the last decades, the idea of tuned liquid dampers (TLD) got an extension and development. Liquid mainly water - is used as damping mass in this type of dampers. TLD is a cheap, simple in construction and environmental friendly damper type. Such dampers also can be used as an additional water reserve for the building water supply and the fire-fighting systems.
The use of TLD in high-rise building started to increase in the last decade. Main types and ways of improvement of TLD are observed in consequent sections.

\section{OVERVIEW OF TUNED LIQUID DAMPERS}

Liquid motion is a complex process with many parameters and effects that generally is described with the fluid dynamics laws. TLD properties can be widely changed using different shapes of water tanks with or without additional barriers inside.

Usually liquid dampers are strictly connected to the main structure. Liquid motion inside the damper causes oscillations in counter phase to main structure and corresponding damping effect.

\section{A. Tuned liquid column dampers (TLCD)}

One of the most widespread types of liquid dampers is tuned liquid column damper (TLCD). TLCD is Ushaped tube filled with liquid. Liquid flows from one vertical column to the other creating horizontal damping force due to impact on vertical walls and friction between liquid and tube in horizontal part. Liquid motion in TLCD can be well described by hydraulic laws. Due to this TLCD are well investigated and used in engineering practice.

For some time similar dampers are used in naval architecture for ship stability and are called antiroll tanks. In this case, special pipes connect two tanks along sides of the ship. 


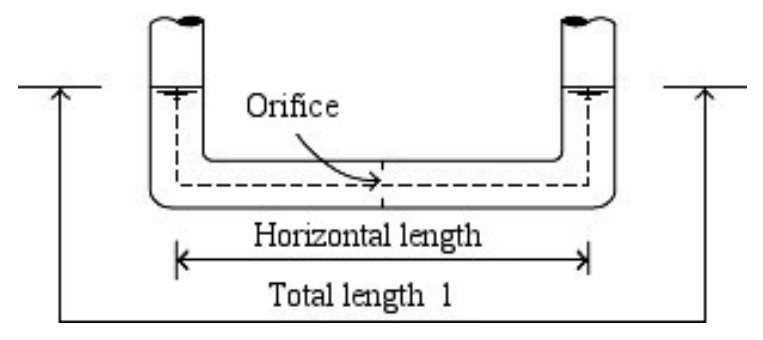

Fig. 1. Principal structure of TLCD [25].

Natural oscillation frequency of tuned liquid column damper is

$$
\omega=\sqrt{2 g / l}
$$

where 1 is total length of a water column. Therefore, the adjustment of such dampers to particular structure is simple, by adding or draining some water from it.

However, this simple damper type also has its disadvantages. Firstly, TLCD is planar structure that works only in one direction. Therefore, for real structures that oscillate in all directions improvements should be made. Secondly, TLCD produces relatively small damping force to their own mass comparing to other damper types. Thirdly, TLCD oscillates and creates a significant damping effect in only one frequency. Studies have shown that considerable TLCD damping effect is obtained only if damper and main structure oscillation frequencies ratio does not exceed $0,9 \ldots 1,1$ interval [3].

Therefore, TLCD are suitable for wind turbines, simple geometry towers and other structures with one dominating oscillation frequency.

Consequently, researchers propose different modifications of TLCD to improve its effectiveness.

\section{B. Modified Tuned Liquid Column Dampers}

Theoretical proposal of TLCD modification is offered by many researchers to raise it effectiveness and range of application.

Placing two TLCD in orthogonal directions damping effect in both main vibration directions will be assumed. Such system is called double tuned liquid column damper (DTLCD) [11].

Circular/torsional tuned liquid column dampers (CTLCD/TTLCD) are proposed for the torsional movement of eccentric structures [1]. In this case damper tube is shaped in circle and should be combined with DTLCD to provide damping effect for all types of main construction motion.

The problem of unidirectional effectiveness of TLCD also can be solved by placing one TLCD on rotating platform that is controlled by electronics. This electronic control provides right orientation of TLCD to ensure damping in the largest oscillation direction. Such damper is called hybrid tuned liquid column damper (HTLCD) [11].

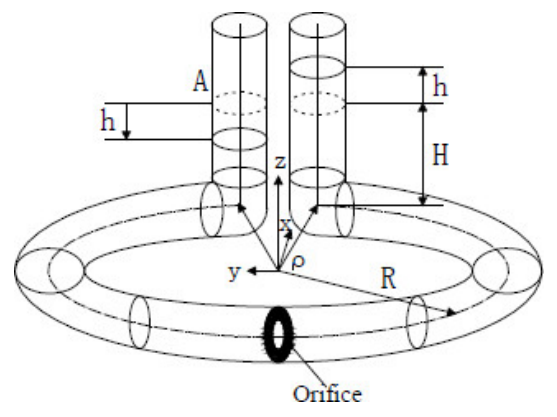

Fig. 2. Scheme of Circular/Torsional TLCD [1].

Of course even more complex shapes of TLCD can be developed and used. Dampers can consist not only from one tube, but from 2 containers connected with different cross section tubes. In this case oscillation frequency depends not only on liquid column length, but on containers and connecting tube geometry. Such dampers sometimes are called liquid column vibration absorbers (LCVA).

To increase the horizontal damping force obtained from liquid motion TLCD can be supplemented with orifices - additional barriers (fig. 1 and fig. 2). These barriers can be fulfilled not only as a plate with openings, but also as a steel ball inside damper [20] or in the other ways.

Valve that changes free tube cross section can be used instead of an orifice. Such valve allows easy to control damper parameters. The valve can be made with computer control which will change damper parameters according to the dominating structure oscillation mode at the moment [30]. Computer controlled dampers with variable properties are called semi-active dampers, opposite to the passive dampers without real time control.

If we hermetically seal both TLCD ends, we will ensure air pressure changes in the end zones during oscillations. Practically additional gas spring to water column in the damper is provided. Such dampers are called pressurized tuned liquid column dampers (PTLCD) or tuned liquid column gas dampers (TLCGD) [13]. This damper type extends frequency range of TLCD.

Some researchers propose to replace tight connection between damper and main structure to elastic. It can be fulfilled by hanging platform with TLCD with ropes to main structure. In this case, pendulum type liquid dampers are obtained [12]. Actually, it is a combination of TLCD and mass damper and it functions according to the more complex motion laws.

To provide effective damping at many frequencies multiple tuned liquid column dampers (MTLCD) are proposed - a series of liquid column dampers of different sizes simultaneously connected to the main structure. It is an unsophisticated approach to multifrequency problem and it corresponds with multiple mass damper idea, which is fulfilled in some high-rise 
buildings. In this case, several different dampers can be located along height of building on different levels. Size of each damper can be consequently reduced and their parameters can be optimized for the particular structure oscillation mode.

Some researchers offer to use magneto-rheological fluid or electro-rheological fluids in $\operatorname{TLCD}[5,11,19]$. In this case, electromagnetic field generating devices can be placed around TLCD tube. Electromagnetic field can cause changes of rheological properties of fluid and as a result changes of damper mechanical properties. This process under computer control allows adjusting damper properties to most critical structure oscillations at the particular moment. These types of dampers are called magneto-rheological dampers (MR-TLCD) or electro-rheological dampers (ER-TLCD). Similar idea of the damper properties adjustment is used in modern top class vehicle semiactive suspensions.

Mentioned examples show that there are many different routes for TLCD development. At the moment it is hard to predict, what approach will be most effective and which will get practical application in construction industry.

\section{Sloshing liquid dampers (SLD)}

Sloshing dampers have the simplest construction comparing to the other types of liquid dampers. Generally, it is a rectangular or barrel-shaped container with commensurable all three dimensions that is partly filled with liquid. Liquid impacts sidewalls of container generating damping force. Due to simple construction, sloshing dampers are often meant by the term tuned liquid dampers in literature and papers.

However, simple damper construction does not lead to the simple understanding of its mechanic. In SLD happens sloshing - liquid has free surface where waves can arise. Effects of waves, sloshing viscous damping and suppression, sloshing-structure interaction and others occur in this case. Considering that liquid sloshing dynamics is complex developing discipline, precise solution of SLD movement can be hardly obtained in practical case [2].

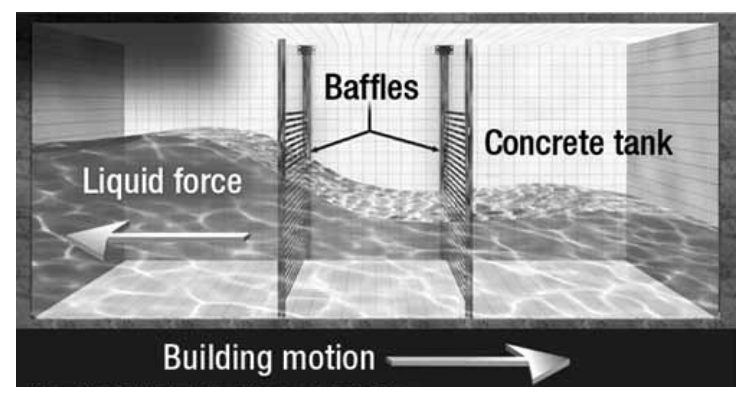

Fig. 3. SLD with additional slat screens (baffles) [23].
As a result, investigations of SLD often are based on experimental studies or simplified calculation models. Widespread SLD simplified calculation model is a tuned mass damper analogy - water in container is represented as solid body suspended on cable (simple pendulum). Such pendulum motion model is well known, but it roughly describes liquid motion.

Development of more accurate practical calculation methods of SLD is an actual objective for researchers and civil engineers [21].

SLD can be divided into shallow or deep dampers according to their dimensions. Liquid motion mechanic differs in these cases. Generally damper effectiveness significantly decreases if water depth to tank length ratio is less than $0,10 \ldots 0,15[10,16]$.

Natural water oscillation frequency in shallow rectangular SLD without barriers according to the linear water wave theory is $[15,16]$

$$
\omega=\sqrt{\frac{\pi g}{l} \cdot \tanh \left(\frac{\pi \cdot h}{l}\right)}
$$

where 1 is length of damper in the direction of oscillations, $\mathrm{h}$ is water depth and $\mathrm{g}$ is acceleration of free fall. Any changes of damper geometry accordingly changes oscillations frequency.

To improve SLD effectiveness and enlarge damping force construction can be supplemented by additional slat screens (baffles) - additional barrier in the container, which receives a part of liquid motion force. Such baffles make liquid motion in damper even more complex, but its effectiveness is generally proved $[9,24,27]$. Additional barriers can increase energy dissipation up to $60 \%$ [2].

Most suitable structures for SLD practical application are high-rise towers, where damper is also additional water tank for fire-fighting system.

\section{Bi-directional liquid dampers (BLD)}

For TLCD it is possible to use U-shaped tank with considerable dimension transverse to damper working plane instead of a tube (fig. 4). In this case in TLCD transversal direction sloshing effect occurs. Such dumper works in one direction as TLCD, but in other as SLD. This construction is called a bi-directional liquid damper (BLD) or combined liquid damper [6, 29].

Main practical advantage of this damper is that one damper ensures practical effect in both directions and effectively uses space. 


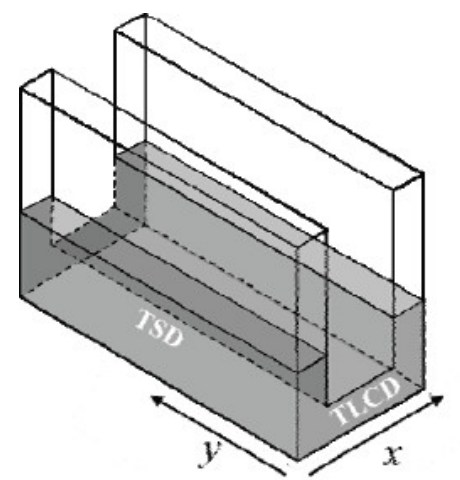

Fig. 4. Bi-directional liquid dampers (BLD) [6]

Additionally, to use space even more effectively, in the middle of BLD can be placed one more rectangular liquid container - sloshing damper. Practically it will be one big liquid rectangular container divided by inner walls into separated different type dampers.

\section{WAYS OF IMPROVEMENT OF TUNED LIQUID DAMPERS}

One of the main disadvantages of currently examined liquid dampers is that only one main oscillation frequency is damped. This is not enough for the structures, where simultaneously different vibration modes are essential. Even for structures with one main oscillation mode multi-frequency dampers should be useful, because structure oscillation frequency can be variable in some range due to different factors and it can be hard to perfectly tune damper for specific structure. Therefore, creating an effective multi-frequency liquid damper is a relevant problem.

Some authors offer using multiple liquid dampers simple incensement of damper amount with different properties. Consequently size of one damper and it effectiveness reduces, but total required space increases. This is a main disadvantage for this approach, especially noting that damper mass and structure mass ratio should reach definite values to provide considerable damping effect $(3 \ldots 4 \%[4,18])$. In addition, it is important to notice that the damper, which has positive effect on one frequency, could create negative oscillations increasing effect on the other frequencies. This feature obliges to choose MTLCD separate damper parameters especially carefully.

Other way to multiply oscillation frequencies damping is semi-active damper creation - damper with computer adjustable properties at any particular moment for the most critical oscillations. Properties adjustment can be done by changing orifices or slat screen dimensions or position, or using magnetorheological / electro-rheological fluids with variable electromagnetic field. It is complicated to fulfill this elegant idea technically in practice. Semi-active damper should have interconnected oscillation sensors strictly strengthened to main structure in different places, movable or variable details in damper and computer control with corresponding software. Practical realization of such damper would be a serious task in any particular case.

Using more complex shapes of water dampers, with special barriers, could be one of the ways to solve the problem and create multi-frequency dampers.

Sloshing damper divided with significant slat screens (baffles) into several partitions combines different liquid motions - a part of motion energy causes waves inside each partition, but another part causes waves along whole damper [24]. Choosing relevant shape and amount of barriers inside SLD dampers could help to develop passive multifrequency damper.

Impact of sloshing damper container and barrier shape changes on damping properties is less investigated. Some researcher investigated influence of SLD slope bottom on its properties. It was found that slope bottom decreases waves and makes liquid motion more uniform $[14,28]$. This example shows how even small changes of damper container shape significantly affects oscillation parameters.

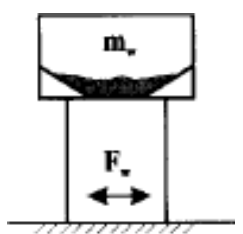

Fig. 5. SLD with sloped bottom [14]

Developing of dampers and barrier shapes could help in using more complex liquid motion modes for oscillation energy dissipation and damping of main structure. This approach would demand complex investigation of new forms of damper containers and barriers using fluid dynamics computational and experimental studies together with structural dynamics studies.

Also, one additional disadvantage of all liquid dampers should be noted - water, liquid that is mainly used in dampers, freezes at negative temperatures. This problem is not essential in heated rooms or can be solved using other liquids or antifreeze additives, but this measure reduces practical advantages of liquid dampers.

Generally, effectiveness of a damper increases together with damper and structure masse ratio. Some studies show that dampers mass must be at least 3-4\% of structure mass to provide significant effect $[4,18]$. This factor limits application area of liquid dampers for example, for heavy reinforced concrete high-rise building large damper, which that requires a lot of space and produces additional load on columns and foundation, is necessary. On the other hand, relatively small damper will be enough for light structures - 
steel masts and lattice towers, footbridges etc. Damper most effective mass ratio investigation would be a relevant research aim.

Practical application of TLD to different structures - high-rises [22, 23], bridges [8], wind turbines [26], floating platforms [17] etc. is investigated. However, less attention is paid to light lattice towers vibration damping, where oscillation problem is relevant. Such towers often are used as communication or observation towers and correspondingly have high allowable deformation requirement from telecommunication industry or human comfort viewpoint [7]. Simple and reasonably cheap TLD for light lattice tower would find wide practical application.

Generally two main approaches for liquid damper development can be marked out - creation of more complex semi-active or active dampers with parameters adjustable for instant moment oscillations and development of more effective shapes of simple passive dampers.

\section{CONCLUSIONS}

Nowadays liquid oscillation dampers are in active development stage. Researchers and engineers seek for optimal form and construction of liquid dampers.

Comparing large amount of research articles dedicated to liquid dampers it is possible to claim, that more attention is given to tuned liquid column dampers and their development, than to sloshing dampers. I suppose, that it can be explained with more simple and clear TLCD functioning principles.

Two main liquid damper development directions that cloud provide multi-frequency damping can be marked out. First is - creating more complex semiactive or active dampers under computer control with parameters adjustable to most critical oscillations mode at instant moment. In this case, different techniques to adjust damper parameters are proposed and examined.

Second way is developing effective shapes of containers and inner barriers of passive dampers, which provide more complex liquid motion modes for oscillation energy dissipation and damping of main structure. This approach is not investigated well and seems perspective; however, it demands complex studies of dampers with fluid dynamics and structural dynamics methods as well as development of practical but precise calculation procedure.

Passive liquid dampers could be effective solution for excessive vibration reduction in light lattice towers.

\section{REFERENCES}

[1] Linsheng Huo and Hongnan Li, Seismic Response Reduction of Eccentric Structures Using Liquid Dampers, Vibration Analysis and Control - New Trends and Developments, Dr. Francisco Beltran-Carbajal (Ed.), InTech, 2011, ISBN: 978953-307-433-7.
[2] Raouf A. Ibrahim, Liquid Sloshing Dynamics, Cambridge University Press, 2005.

[3] A. Farshidianfar, P. Oliazadeh, H.R. Farivar, "Optimal Parameter's Design in Tuned Liquid Column Damper", 17th. Annual (International) Conference on Mechanical Engineering - ISME2009, May, 2009, University of Tehran, Iran.

[4] P. Banerji, Tuned liquid dampers for control of earthquake response, 13th World Conference on Earthquake Engineering, Vancouver, B.C., Canada, August 1-6, 2004, Paper No. 1666.

[5] H. Masuda, T. Oyamada and T. Sawada, Experimental study on damping characteristics of the tuned liquid column damper with magnetic fluid, 13th Int. Conf. on Electrorheological Fluids and Magnetorheological Suspensions. Journal of Physics: Conference Series 412 (2013) 012049.

[6] H.R. Lee and K.W. Min, Reducing Acceleration Response of a SDOF Structure with a Bi-Directional Liquid Damper, The Proceedings of the Twelfth East Asia-Pacific Conference on Structural Engineering and Construction - EASEC12. Procedia Engineering, vol. 14, pp. 1237-1244, 2011.

[7] L. Gaile, Analysis of Dynamic Parameters of Observation Towers in Latvia, Environment, Technology, Resources: Proceedings of the 9th International Scientific and Practical Conference. Vol.II, Latvia, Rēzekne, 20-22 June, 2013. Rēzekne: RA Izdevniecība, 2013, pp.58-64.

[8] M. Reiterer, Control of pedestrian-induced bridge vibrations by tuned liquid column dampers, Proceedings of the Third European Conference on Structural Control, 3ECSC, 12-15 July 2004, Vienna University of Technology, Vienna, Austria.

[9] S.H. Crowley, R. Porter, Optimal screen arrangements for a tuned liquid dampe", International workshop on water waves and floating bodies 26, 2011, Athens.

[10] Sheng Dong, Hua Jun Li, Tomotsuka Takayama, Characteristics of Tuned Liquid Damper For Suppressing Wave-Induced Vibration, Proceedings of the Eleventh (2001) International Offshore and Polar Engineering Conference, 1722 June, Stavanger, Norway.

[11] B. Nanda, "Application of tuned liquid damper for controlling structural vibration" M.S. thesis, National Institute of Technology, Rourkela, India, 2010.

[12] A. Sarkar A, O.T. Gudmestad, "Pendulum type liquid column damper (PLCD) for controlling vibrations of a structure Theoretical and experimental study", Engineering Structures, vol. 49, pp. 221-233, 2013.

[13] Ch. Fu and F. Ziegler, "Vibration prone multi-purpose buildings and towers effectively damped by tuned liquid column-gas dampers", Asian journal of civil engineering (building and housing), vol. 10, pp. 21-56, no. 1, January 2009.

[14] D.E. Olson and D.A. Reed, "A nonlinear numerical model for sloped-bottom tuned liquid dampers", Earthquake Engineering \& Structural Dynamics, vol. 30, Issue 5, pp. 731743, May 2001.

[15] D. Reed, J. Yu, H. Yeh and S. Gardarsson, "Investigation of Tuned Liquid Dampers under Large Amplitude Excitation", Journal of Engineering Mechanics, vol. 124, Issue 4, pp. 405413, April 1998.

[16] E. Bhattacharjee, L. Halder, R.P. Sharma, “An experimental study on tuned liquid damper for mitigation of structural response", International Journal of Advanced Structural Engineering (IJASE), vol. 5, Issue 1, December 2013.

[17] H.H. Lee, S.-H. Wong, R.-S. Lee, "Response mitigation on the offshore floating platform system with tuned liquid column damper", Ocean Engineering, vol. 33, Issues 8-9, pp. 11181142, June 2006.

[18] Jong-Cheng Wua, Ming-Hsiang Shihb, Yuh-Yi Lina, YingChang Shenc, "Design guidelines for tuned liquid column damper for structures responding to wind", Engineering Structures, vol. 27, Issue 13, pp. 1893-1905, November 2005.

[19] J.Y. Wang, Y.Q. Ni, J.M. Ko, B.F. Spencer Jr, "Magnetorheological tuned liquid column dampers (MR-TLCDs) for vibration mitigation of tall buildings: modelling and analysis 
of open-loop control", Computers \& Structures, vol. 83, Issues 25-26, pp. 2023-2034, September 2005.

[20] K.A. Al-Saif, K.A. Aldakkan, M.A. Foda, "Modified liquid column damper for vibration control of structures", International Journal of Mechanical Sciences, vol. 53, Issue 7, pp. 505-512, July 2011

[21] K.M. Shum, "Closed form optimal solution of a tuned liquid column damper for suppressing harmonic vibration of structures", Engineering Structures, vol. 31, Issue 1, pp. 84 92, January 2009

[22] K.-W. Min, H.-S. Kim, S.-H. Lee, H. Kim, S.K. Ahn, "Performance evaluation of tuned liquid column dampers for response control of a 76-story benchmark building", Engineering Structures, Volume 27, Issue 7, Pages 11011112, June 2005.

[23] M. Nadine, "A Sleek Skyscraper in San Francisco Raises the Profile of Performance-Based Design", Architectural Record, June 2008.

[24] O. M. Faltinsen, R. Firoozkoohi, A. N. Timokha, "Analytical modeling of liquid sloshing in a two-dimensional rectangular tank with a slat screen", Journal of Engineering Mathematics, vol. 70, Issue 1-3, pp 93-109, July 2011 .

[25] P. Ahadi, M. Mohebbi and K. Shakeri, "Using Optimal Multiple Tuned Liquid Column Dampers for Mitigating the
Seismic Response of Structures", ISRN Civil Engineering, vol. 2012, Article ID 592181, 6 pages.

[26] S. Colwell, B. Basu, "Tuned liquid column dampers in offshore wind turbines for structural control", Engineering Structures, vol. 31, Issue 2, pp. 358-368, February 2009.

[27] S. Crowley, R. Porter, "An analysis of screen arrangements for a tuned liquid damper" Journal of Fluids and Structures, vol. 34, pp. 291-309, October 2012.

[28] S. Gardarsson, H. Yeh and D. Reed, "Behavior of SlopedBottom Tuned Liquid Dampers", Journal of Engineering Mechanics, vol. 127, No. 3, pp. 266-271, March 2001.

[29] S.-K. Lee, K.-W. Min, H.-R. Lee, "Parameter identification of new bidirectional tuned liquid column and sloshing dampers", Journal of Sound and Vibration, vol. 330, Issue 7, Pages 1312-1327, 28 March 2011.

[30] S.K. Yalla, A. Kareem, J.C. Kantor, "Semi-active tuned liquid column dampers for vibration control of structures", Engineering Structures, vol. 23, pp. 1469-1479, 2001.

[31] T. Tanaka, M. Yamamoto, T. Katayama, K. Nakahira, K. Yamane, Y. Shimano, K. Hirayama, "Recent Applications of Structural Control Systems to High-Rise Buildings", Earthquake Engineering and Engineering Seismology, Vol. 4, No. 1, pp. 75-93. 